\title{
ECC
}

\section{Green synthesis and characterization of silver nanoparticles using Scrophularia Striata extract}

\author{
Tayeb AB Matina, Nahid Ghasemia,*, Keivan Ghodratib, Majid Ramezania \\ aDepartment of Chemistry, Arak Branch, Islamic Azad University, Arak, Iran \\ ${ }^{b}$ Department of Chemistry, Kermanshah Branch, Islamic Azad University, Kermanshah, Iran
}

Received: 27 April 2019, Accepted: 26 May 2019, Published: 1 November 2019

\begin{abstract}
Here, green synthesis of silver nanoparticles (NPs) using aqueous extract of Scrophularia Striata was demonstrated. In order to obtain the best formation conditions of NPs, different physicochemical parameters such as volume of the extract, silver ion concentration, temperature and reaction time were studied. Synthesized resultant NPs were characterized using UV, SEM, TEM, EDX, XRD, FT-IR and DLS analyses. A color change to brown after adding the extract to the silver nitrate solution was observed which indicated the formation of silver NPs. The synthesized silver NPs by Scrophularia Striata extract showed the highest absorbance at $426 \mathrm{~nm}$. Plants have been used as stabilizing and reducing agents for NPs, due to their antioxidant properties and many secondary compounds.
\end{abstract}

Keywords: Green synthesis; silver nanoparticles; Scrophularia Striata; silver nitrate.

\section{Introduction}

Nanotechnology refers to the design, characterization, production, and application of nanoscale structures and systems (1-100 $\mathrm{nm})$ by controlling shape and size [1]. Conventional ways to produce NPs include chemical, physical, and biological methods have been used for many years [2]. In recent years, biological synthesis using fungi, bacteria and plant extracts have attracted attention because these methods are simple, low cost, high efficient, non-toxic and environmentally friendly [3-6]. Many papers on the biological synthesis of silver NPs have been reported using microorganisms, such as bacteria, fungi and plants; this is due to the antioxidant or reducing properties of these

*Corresponding author: Nahid Ghasemi

Tel: +98 (86) 34135421, Fax: +98 (86) 34135421

E-mail:n-ghasemi@iau-arak.ac.ir, anahid3@gmail.com materials, which reduce metal compounds. However, compared to different biological methods for the synthesis of silver NPs, microbial synthesis is not industrially feasible, due to the need for highly disinfected and maintenance conditions. As a result, due to the ease of improvement, less and more precise biological process, and cell culture maintenance, the use of plant extracts for this purpose has a potential advantage over microorganisms.

In addition, the use of herbal extracts reduces the cost of isolating microorganisms and their culture medium [2,7]. Because of the abundance and lack of need to specific conditions and nutrients for growth, plants are considered to be a good 
option for the green synthesis of NPs, which has many advantages over physical and chemical methods and is environmentally friendly [8].

The completeness of the reaction, the low reaction time, the production of NPs in various shapes and the uniformity of their size are among the other benefits of using plants for the green synthesis of NPs.

Several studies have demonstrated the synthesis of silver NPs using plants; Gardea et al. (2003) reported, for the first time, the production of silver NPs by plants [9]. Chenopodium album, Camellia sinensis and Rhus coriaria could also reduce silver ions in sizes below $50 \mathrm{~nm}$ [10-12]. The silver NPs synthesized from Garlic and Pinus eldarica with sizes of 10-40 and 20$30 \mathrm{~nm}$ showed good antimicrobial properties against some bacteria $[13,14]$.

The present study aims at studying the high potential of Scropholaria Striate leaf in the biosynthesis of silver NPs and its effect on several species of human pathogens (Figure 1).

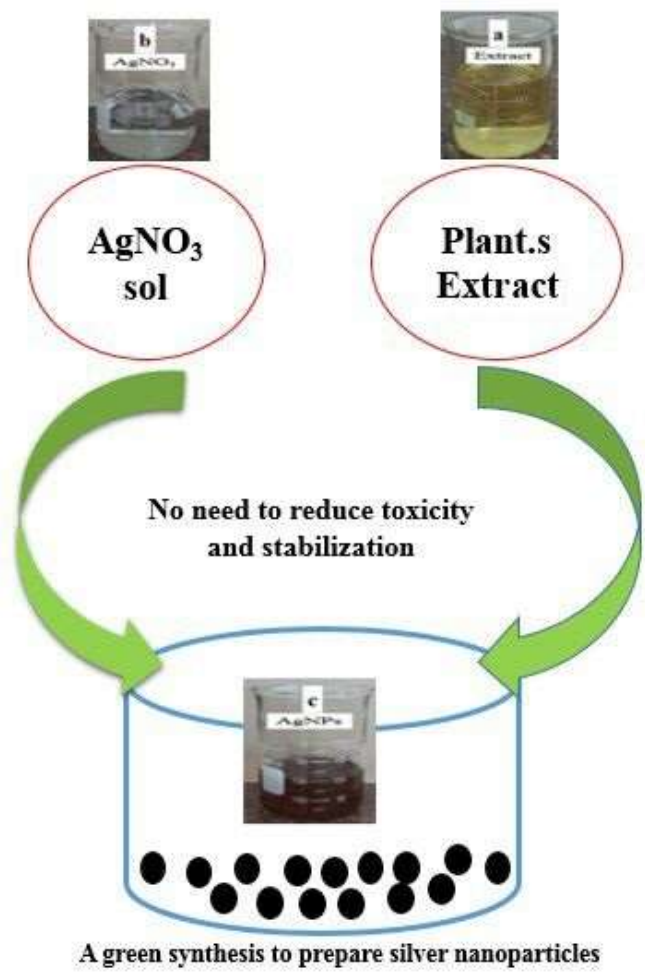

Figure 1. Synthesis of silver NPs by Scropholaria Striate

\section{Experimental \\ General}

Chemicals and microorganisms used: All chemicals used had high purity. Silver nitrate $\left(\mathrm{AgNO}_{3}\right)$ was purchased from Merck (Germany). Doubledistilled water was used for washing the materials and making the solution. FT-IR spectra were recorded with a Nicolet Avatar $370 \quad$ FT-IR spectrometer. Transmission electron microscopy (TEM) was performed with a Leo $912 \mathrm{AB}(120 \mathrm{kV})$ microscope ( Zeiss, Germany). Elemental compositions were determined with EDX analysis (model 7353, Oxford Instruments, UK), with $133 \mathrm{eV}$ resolution. The crystal structure of the catalyst was analysed using XRD with a Bruker $\mathrm{D}_{8}$ ADVANCE diffractometer using a $\mathrm{Cu}$ target $(\lambda=1.54 \AA)$. 


\section{Preparation of plant extract}

The Scropholaria Striate is a floral, shrub-like herb of the family of mint which is grown up to a height of $40 \mathrm{~cm}$. It was collected from Kermanshah County in Kermanshah province, Iran (Figure 2). A few fresh leaves of the plant were washed with double-distilled water, put away from the sun and kept at the room temperature to dry up. The dried parts were then powdered by an electric mill. For the extraction, $1 \mathrm{~g}$ of powder was added to $100 \mathrm{ml}$ of doubledistilled water for 30 minutes at $40^{\circ} \mathrm{C}$ in a hot bath. After cooling, it was filtered through a Wattman 42 filter paper. To completely remove the suspended particles in the extract, the sample was centrifuged at a speed of $12,000 \mathrm{rpm}$ for 10 minutes.

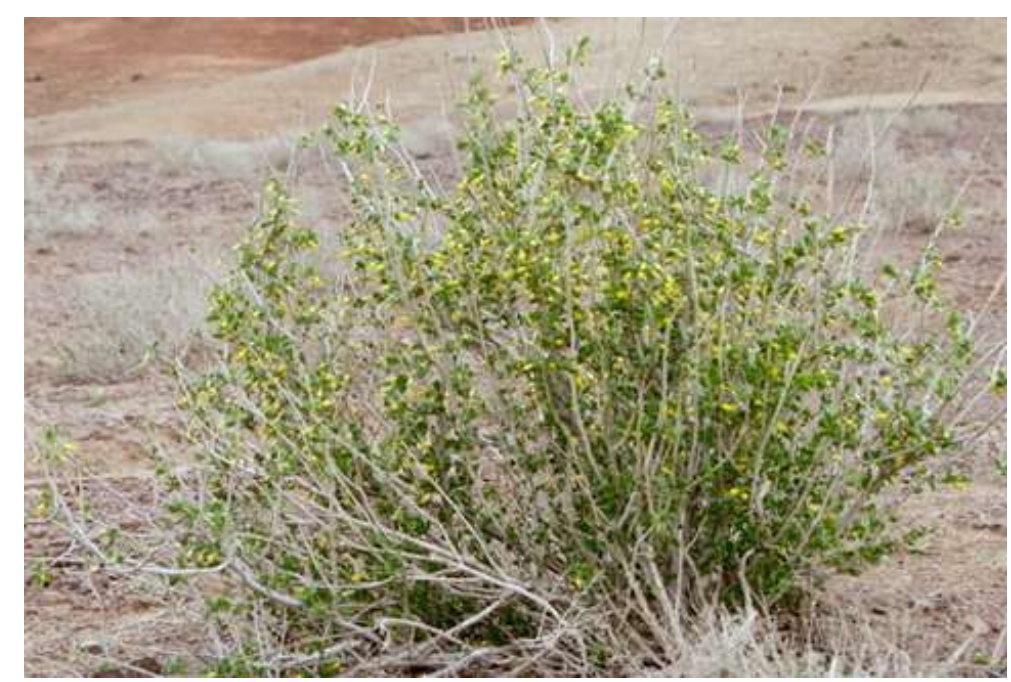

Figure 2. Scropholaria Striate medicinal herbs

\section{Synthesis of silver NPs}

For the synthesis of silver NPs, $2 \mathrm{~mL}$ of Scropholaria Striate extract was added to $4 \mathrm{ml}$ of a $1.0 \mathrm{mM}$ molar $(169.87 \mathrm{mg})$ silver nitrate solution at laboratory temperature. It has been observed that the color of the solution changed to the brown, which indicates the formation of silver NPs. The UV-Vis spectrophotometry was employed to determine and verify optimal conditions for each parameter affecting the synthesis.

Investigating Parameters affecting the Synthesis of Silver NPs

The Effect of extract volume

In order to investigate the effect of the amount of extracts consumed and its optimization, the amounts of $0.1,0.2$, $0.25,0.5,1,1.5,2 \mathrm{~mL}$ of extract were added to $4 \mathrm{~mL}$ of silver nitrate salt at a concentration of $1.0 \mathrm{mM}(169.87 \mathrm{mg})$ and the UV-Vis spectrophotometry which was then employed for all solutions. Finally, the optimum extract volume was selected.

\section{Effect of silver nitrate concentration}

To investigate the effect of silver ion concentration on the synthesis of silver NPs and optimizing it, the optimized amount of extract volume was added to $4 \mathrm{~mL}$ silver nitrate solution with concentrations $(0.5,1,1.5,2,3,5,8)$ $\mathrm{mM}$. The UV-Vis spectrophotometry was then employed for all solutions and the optimal concentration was selected.

\section{Temperature}

In order to investigate the effect of temperature increase on the synthesis of silver NPs and optimizing it, solutions were made according to all the previous optimal conditions and put individually 
at $25,35,45,55,65,75,85{ }^{\circ} \mathrm{C}$ (in an incubator shaker). The UV-Vis spectrophotometry was then employed for all solutions and the optimum temperature was selected.

\section{Time}

In order to study the effect of time on the synthesis of silver NPs and optimizing it, the solution was made through applying all optimized conditions at different times $(10,20$, 30, 40, 50, 60,90, 120 and 180 minutes, from the moment of mixing reagents up to $3 \mathrm{~h}$ later).

The UV-Vis spectrophotometry was then employed for all solutions and the optimal time was selected.

Characterization of synthesized silver NPs

According to researchers, the size and shape of the NPs, as well as the effectiveness of these NPs for antimicrobial properties largely depend on various factors such as extract volume, salt solution concentration, temperature and time. To characterize the silver NPs synthesized in optimal conditions (for extract of Scropholaria Striate with extract volume: $2 \mathrm{~mL}$, concentration of silver nitrate salt: 2.5
$\mathrm{mM}$, temperature: $35^{\circ} \mathrm{C}$, and time: 35 minutes), different techniques such as UV-Visible, Scanning Electron Microscopy (SEM), Transmission Electron Microscopy (TEM), X-ray diffraction Spectroscopy (EDAX), Xray Diffraction (XRD), Fourier Infrared Transformation (FT-IR) Spectrometry and Mechanical Separation Optical (DLS) were used.

\section{Results and discussion}

Optimization of Parameters affecting the Synthesis of NPs

In the initial synthesis of silver NPs using the aqueous extract of the leaf of the Scropholaria striate the plant acted as a reductant and stabilizing agent. Figure 3 shows the UV-Vis spectrum and the color change of the silver NP solution without applying optimal conditions. According to this Figure, at $426 \mathrm{~nm}$ wavelength, which is related to surface plasmon resonance of silver NPs, the extract is missing the peak, which indicates that the peak exists at the desired wavelength only due to the synthesis and existence of silver NPs and the extract does not cause any possible interference in the spectrum of silver NPs.

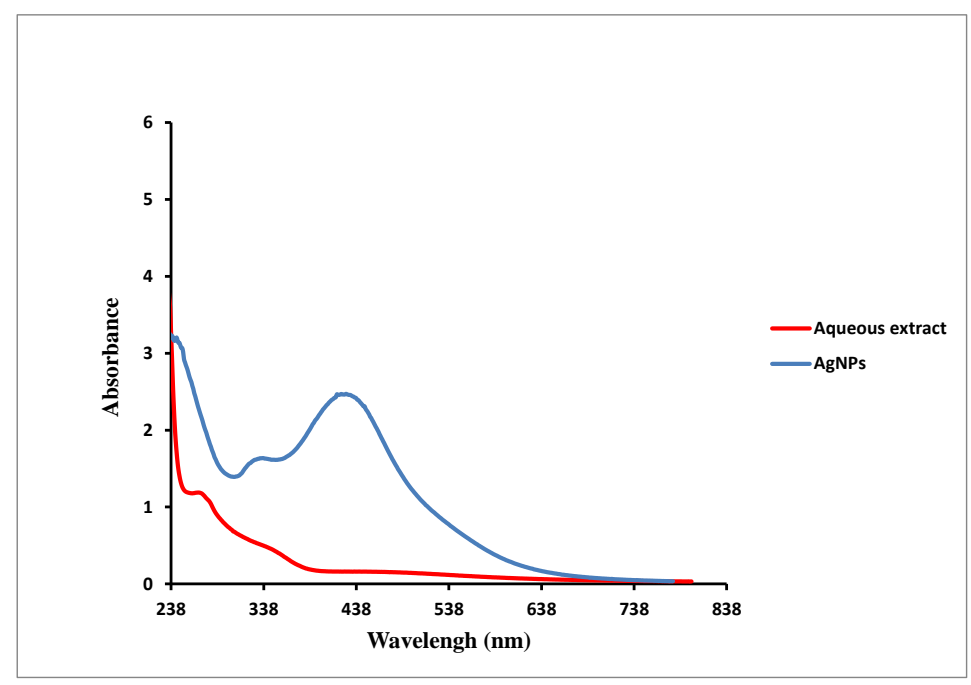

Figure 3. UV-Vis spectrum of synthesis Ag NPs 
Effect of volume Scropholaria Striate Extract on the Synthesis of Silver NPs As shown in Figure. 4, the effect of surface plasmon resonance on the UV spectra is well observed and for all Scropholaria Striate samples, a sharp peak is observed at around $426 \mathrm{~nm}$ wavelength, so that the height of the peaks will increase as the extract volume increases. The reason is that by increasing the volume of the Scropholaria Striate extract, the concentration of groups and molecules such as tannins, phenols, alkaloids, sugars, etc. in the solution is increased [15]. Thus, the reducing and stablizing agents of the formed silver ion are increased. Therefore, according to this Figure, the optimum volume of the Scropholaria Striate extract was $2 \mathrm{~mL}$.

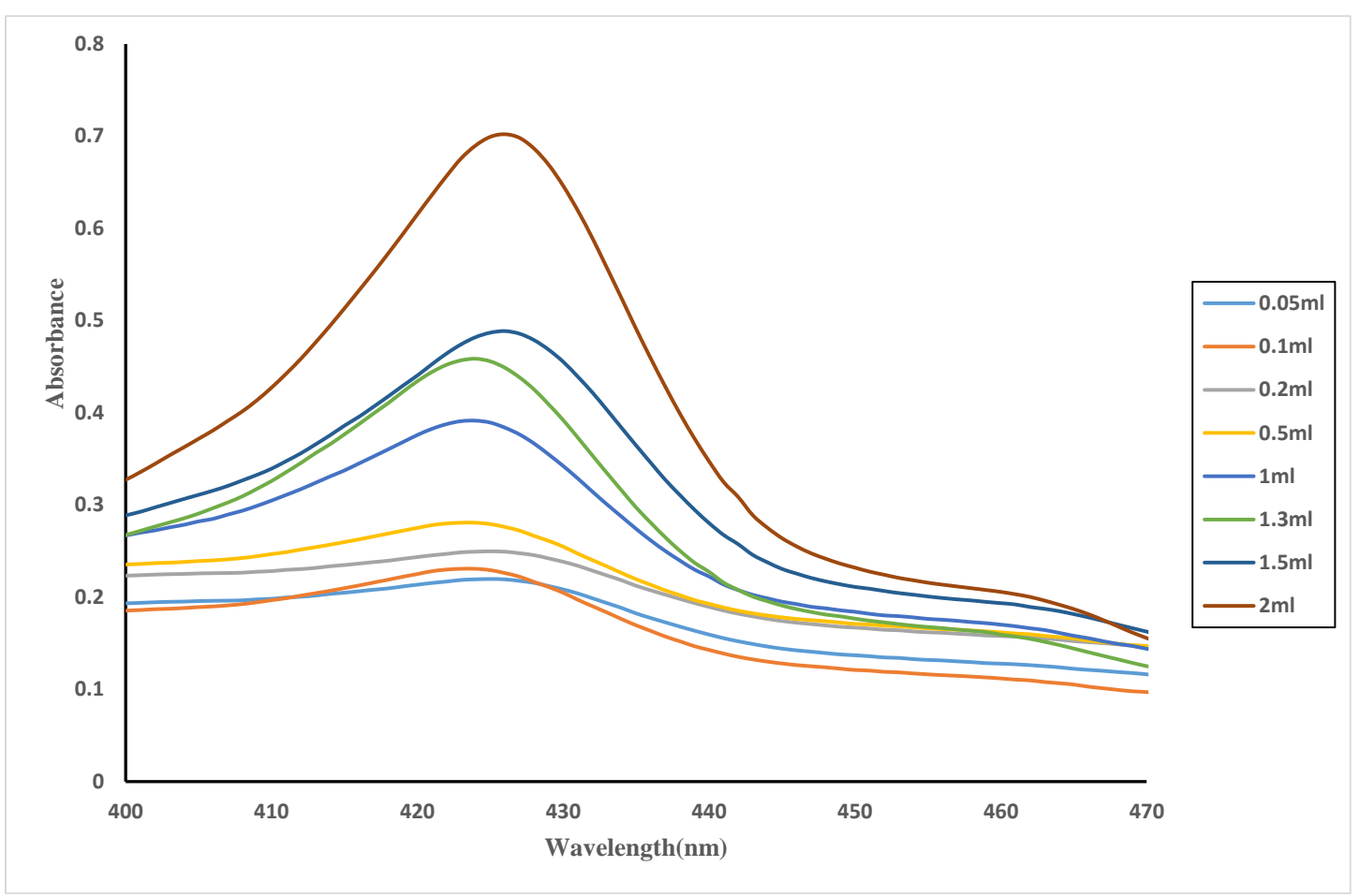

Figure 4. Influence of extract volume Scropholaria Striate on silver NPs synthesis

The effect of concentration of silver nitrate salt on the synthesis of silver NPs

Based on Figure 5 for the Scropholaria Striate extract, the results of the UV spectrum for the effect of metal salt concentration indicate that by increasing the concentration of metal salts, surface plasmon resonance peaks of all samples appeared at $426 \mathrm{~nm}$, and silver NPs were smaller and their dispersion was reduced. Similar results have been reported, such as the effect of the concentration of metal salt on the formation of metal NPs by Alzahrani [16]. The optimum concentration of silver nitrate needed was $2.5 \mathrm{mM}$ based on the observations of the Scropholaria Striate extract. 


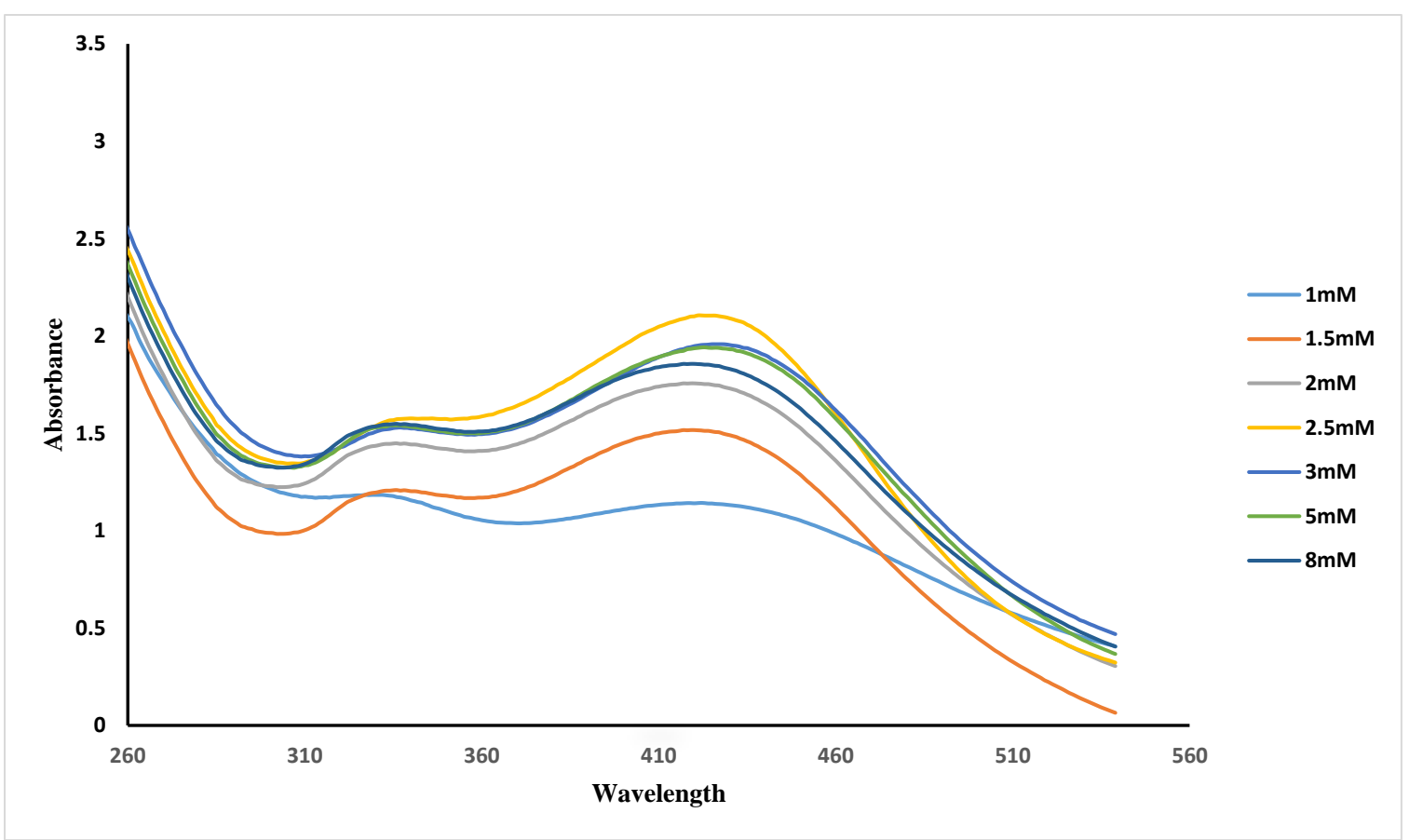

Figure 5. Influence of silver nitrate concentration on silver NPs synthesis

Effect of Temperature on Synthesis of Silver NPS

As Figure 6 shows, wider peaks near the wavelength of $475 \mathrm{~nm}$ are observed at temperatures up to $45^{\circ} \mathrm{C}$, which are sharpened and reach $435 \mathrm{~nm}$ by increasing the temperature. According to the Figure, temperature $35{ }^{\circ} \mathrm{C}$ was selected as the optimum temperature for the synthesis of silver NPs. However, with increasing temperature, peak fluctuation was observed, which is due to the accumulation and clustering of the particles and finally the peak height decrease. A similar result has been reported [17].

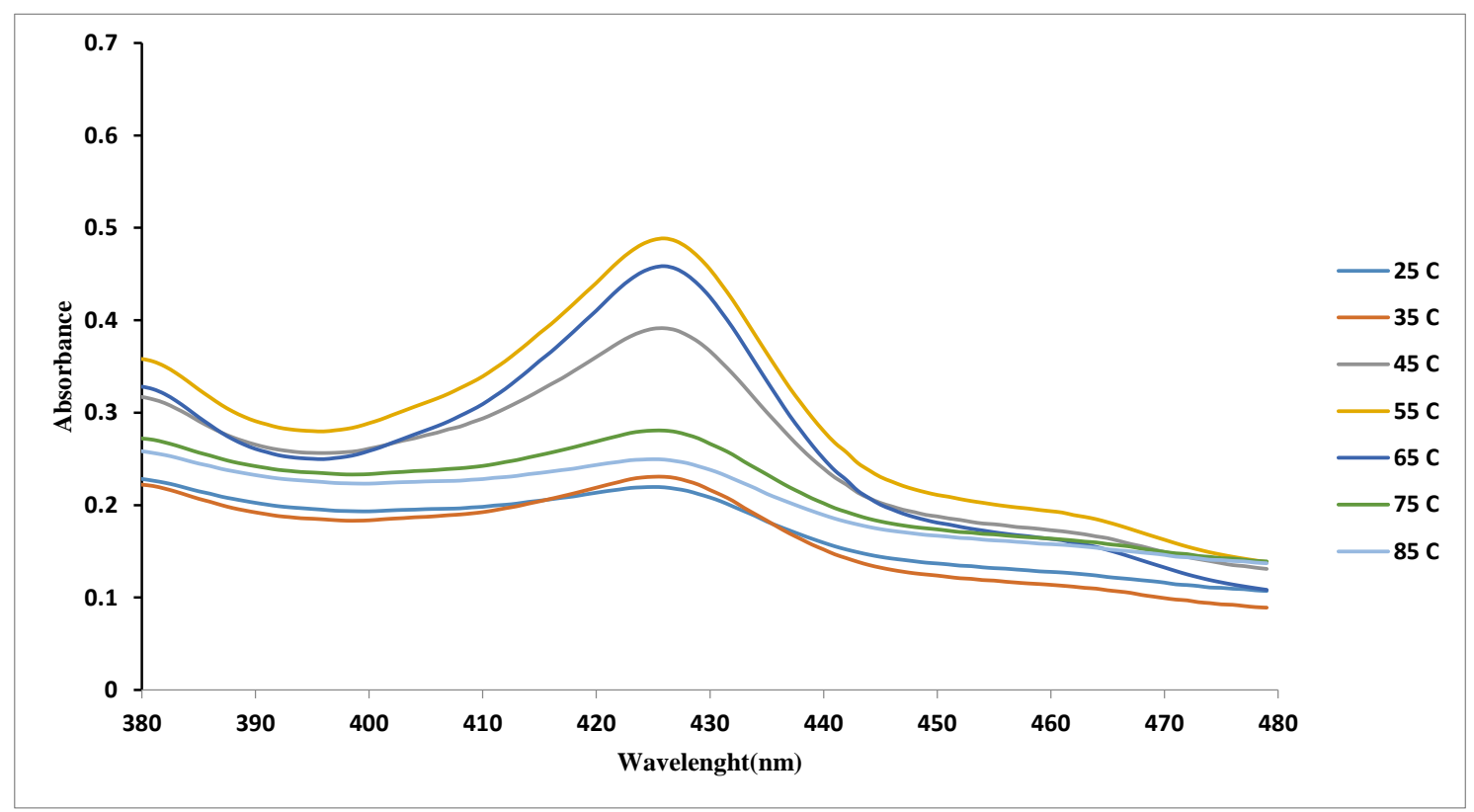

Figure 6. Influence of temperature on silver NPs synthesis 
Effect of Time on Synthesis of Silver NPs

In Figure 7, the UV-Vis spectrum related to the effect of time on the green synthesis of silver NPs is shown by the extract of the Scropholaria Striate. As it is shown, after a 10 minutes of the reaction, a small, weak peak appeared at $430 \mathrm{~nm}$, indicating the formation of silver NPs, but in a small volume with a finite number. As the time increased from 10 minutes to $2030,40,50,60$, 120, 90 and 180 minutes, the absorbing strips become sharper and reach the maximum value after 35 minutes at 426 $\mathrm{nm}$, which results from the remarkable formation of silver NPs. As a result, the optimal time to improve the reaction was 35 minutes, which is similar to that of other researchers in this area [18].

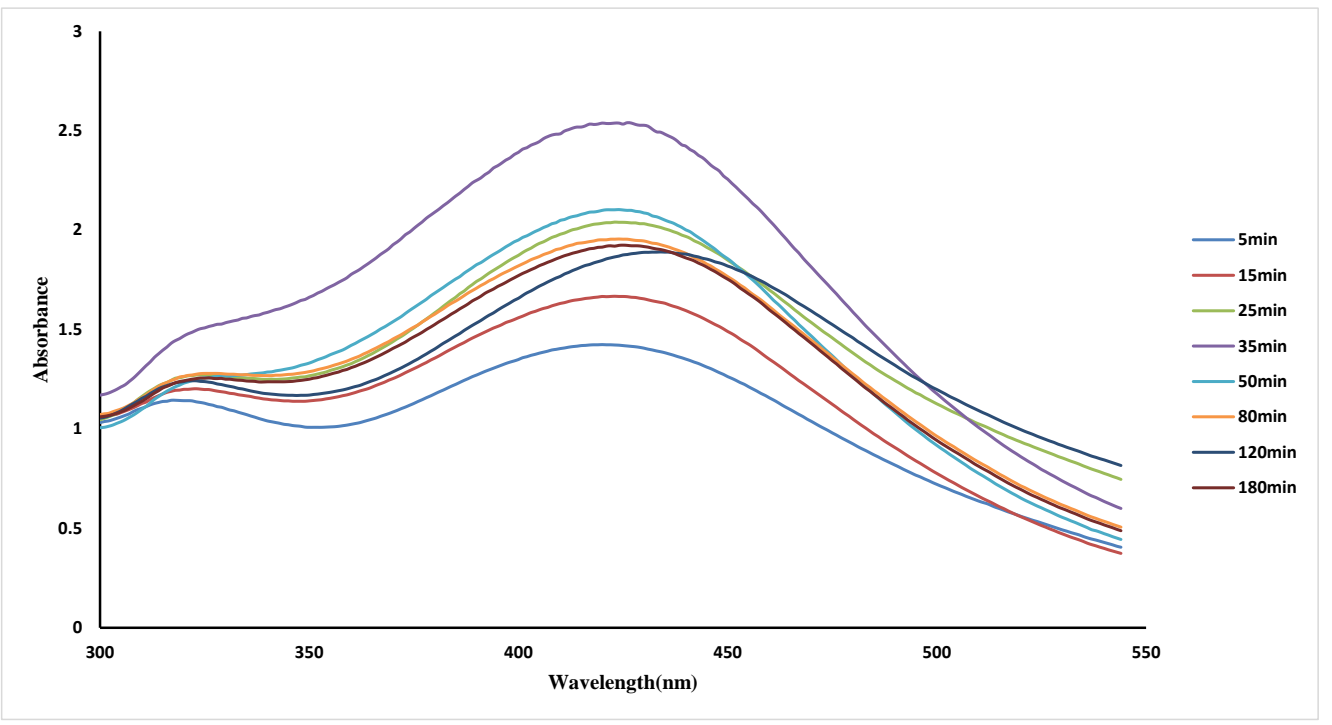

Figure 7. Influence of time on silver NPs synthesis

Characterization of silver NPs presence of cubic silver NPs with a synthesized by Extract of Scropholaria Striate

SEM results

The surface morphology of silver NPs was studied using SEM. In Figure 8, the SEM image clearly confirmed the particle size of about 2.7-47 nm. According to the image, the largest number of particles in this Figure has an average size of about $20 \mathrm{~nm}$. The result of the SEM image is very similar to the previous results [19].

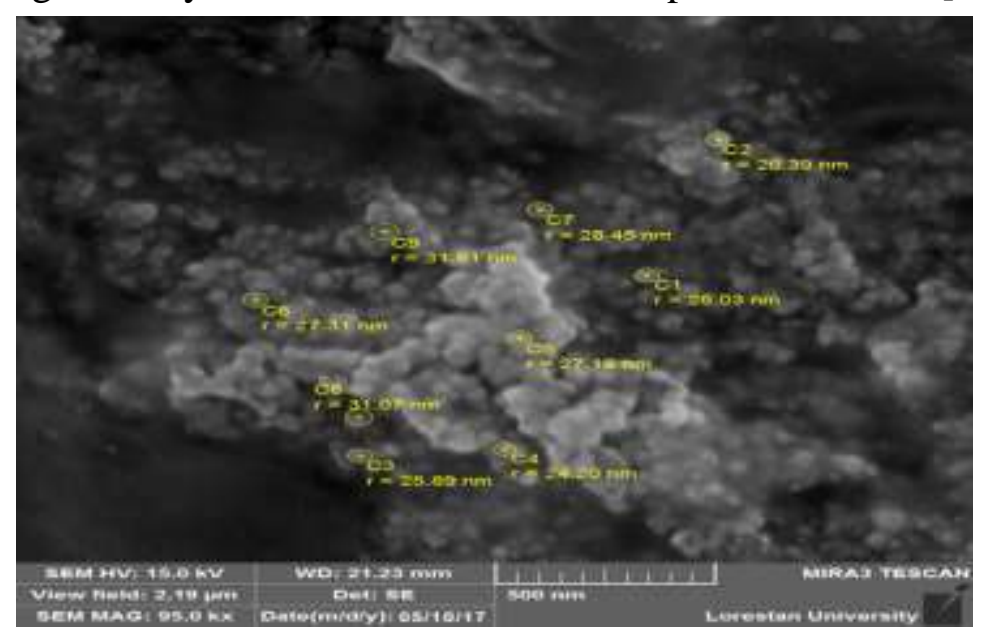

Figure 8. SEM image of Ag NPs using Scropholaria Striate extract 


\section{TEM results}

Figure 9 shows the image of the transmitted electron microscope of silver NPs by applying all optimized conditions. According to this Figure, the TEM of the silver NPs synthesized by the Scropholaria Striate extract was more face-centered cubic (fcc) and the mean particle size was about 20 nanometers [16].

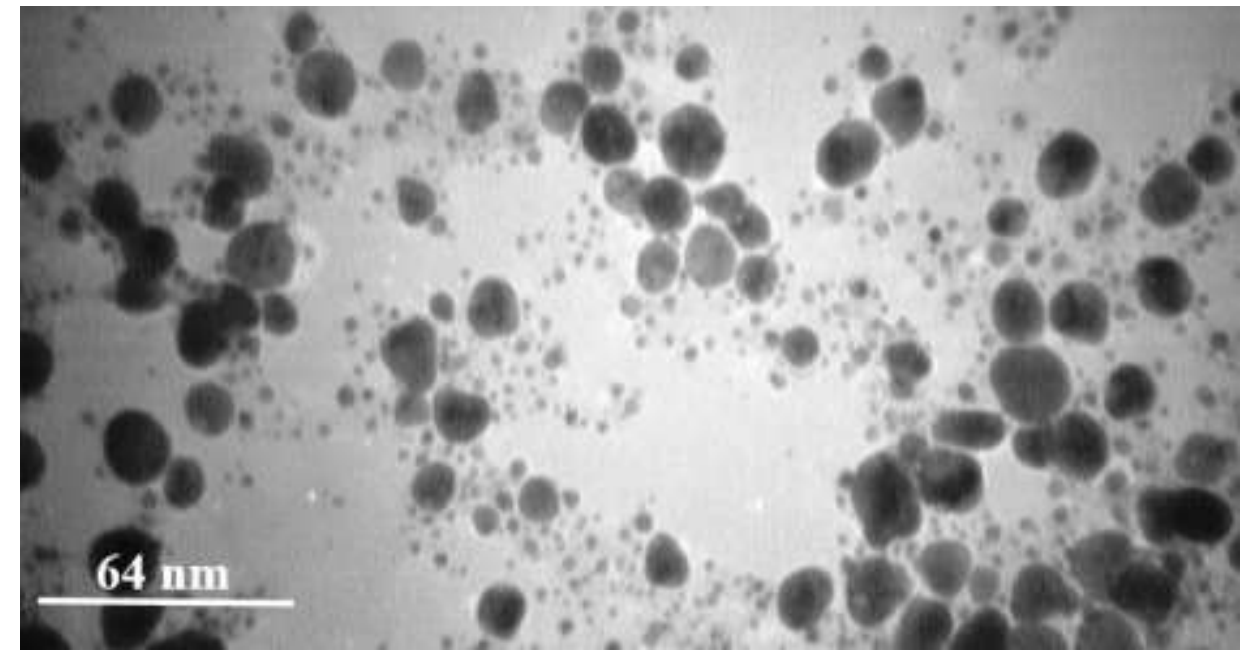

Figure 9. TEM image of Ag NPs using Scropholaria Striate extract

EDAX analysis

The EDAX, which is done by the SEM, shows the amount and presence of elements in places of matter placed under the microscope; that is, analysis of an element that can even be linear elemental analysis (on a hypothetical line in the same SEM image) or an elemental map (the dispersion of the elements in the picture) [21]. As shown in Figure 10, the presence of silver particles and carbon atom is significant, which exactly matches the purpose of this study.

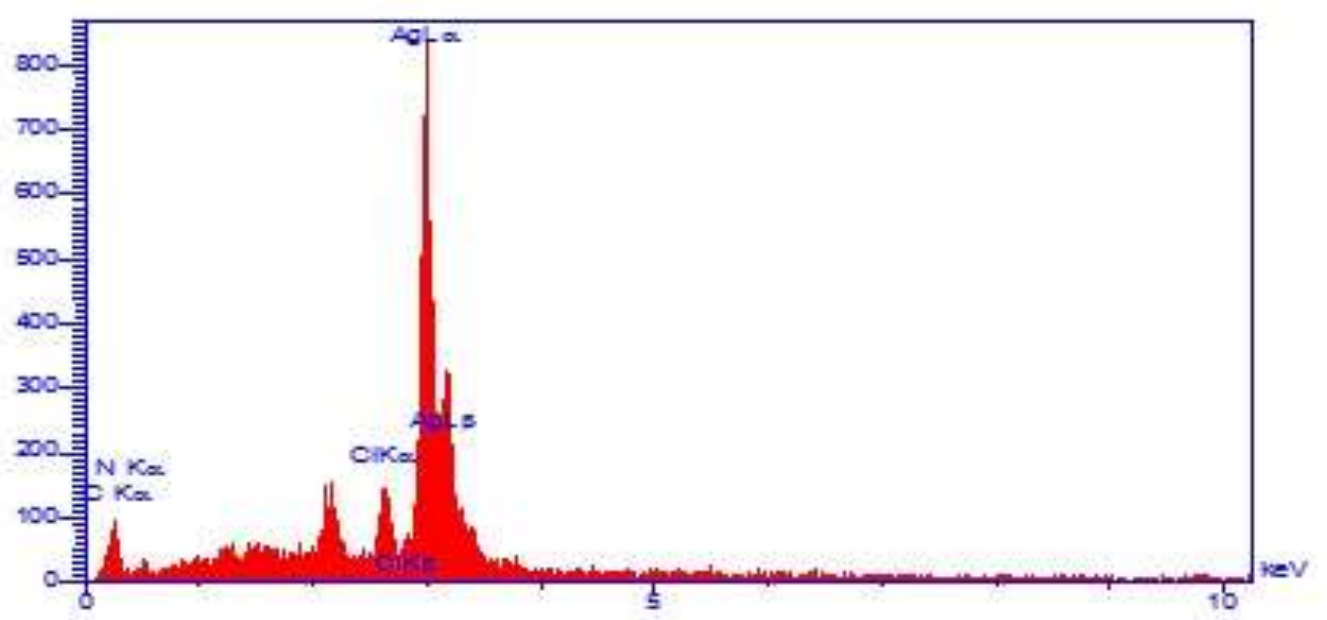



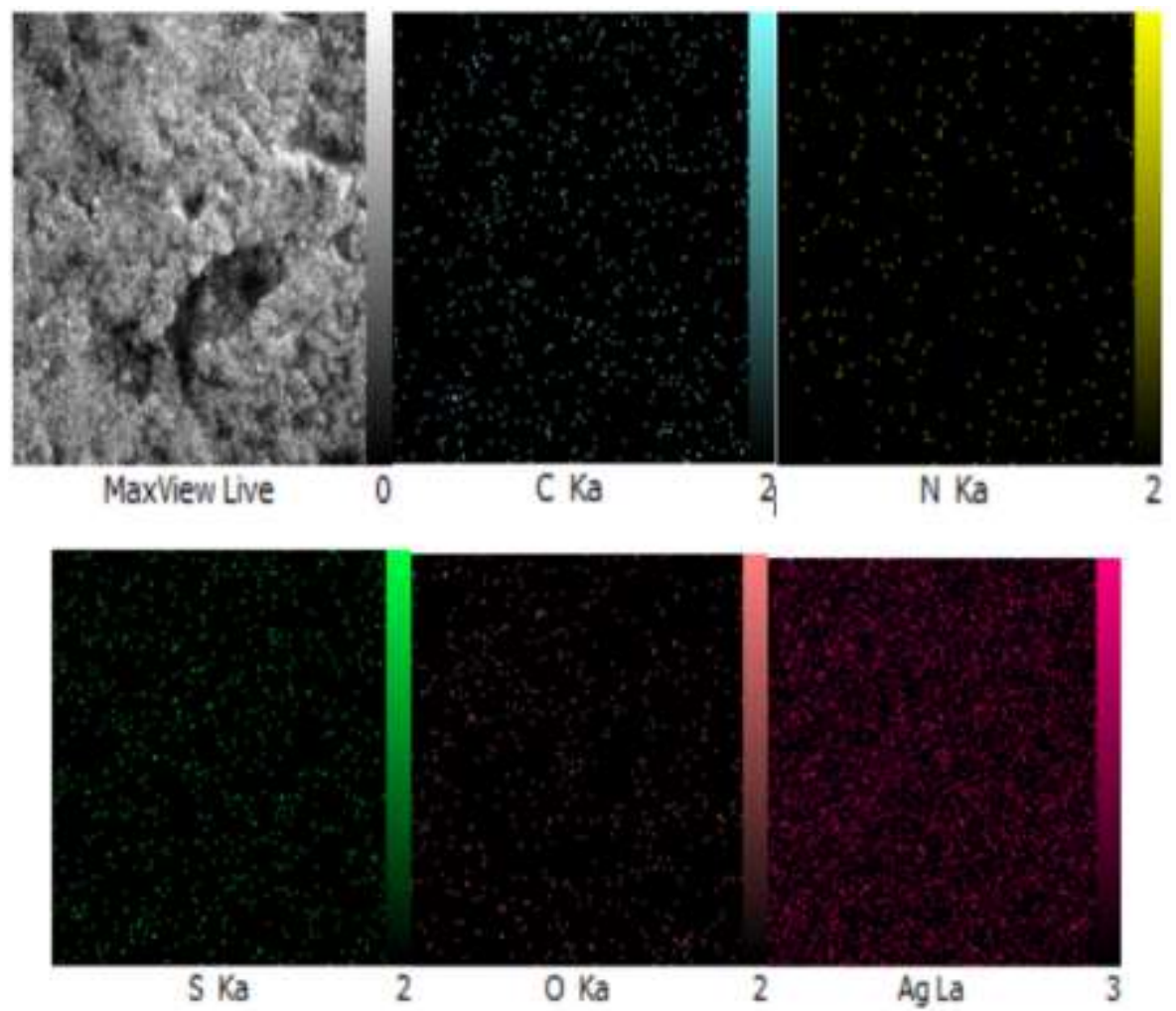

Figure 10. EDX and elemental map of Ag NPs

XRD spectrum survey

$\mathrm{X}$-ray diffraction analysis was used to study the crystalline structure of synthesized silver NPs. As Figure 11 shows, Miller's indices at the levels (111), (200), (220) and (311), which are related to angles 38.306, 44.396,
64.685, and 77.689, respectively, clearly prove that the geometry of the synthesized NPs are face-centered cubic [22]. The presence of sharp peaks in the pattern indicates a high degree of crystallinity for silver NPs.

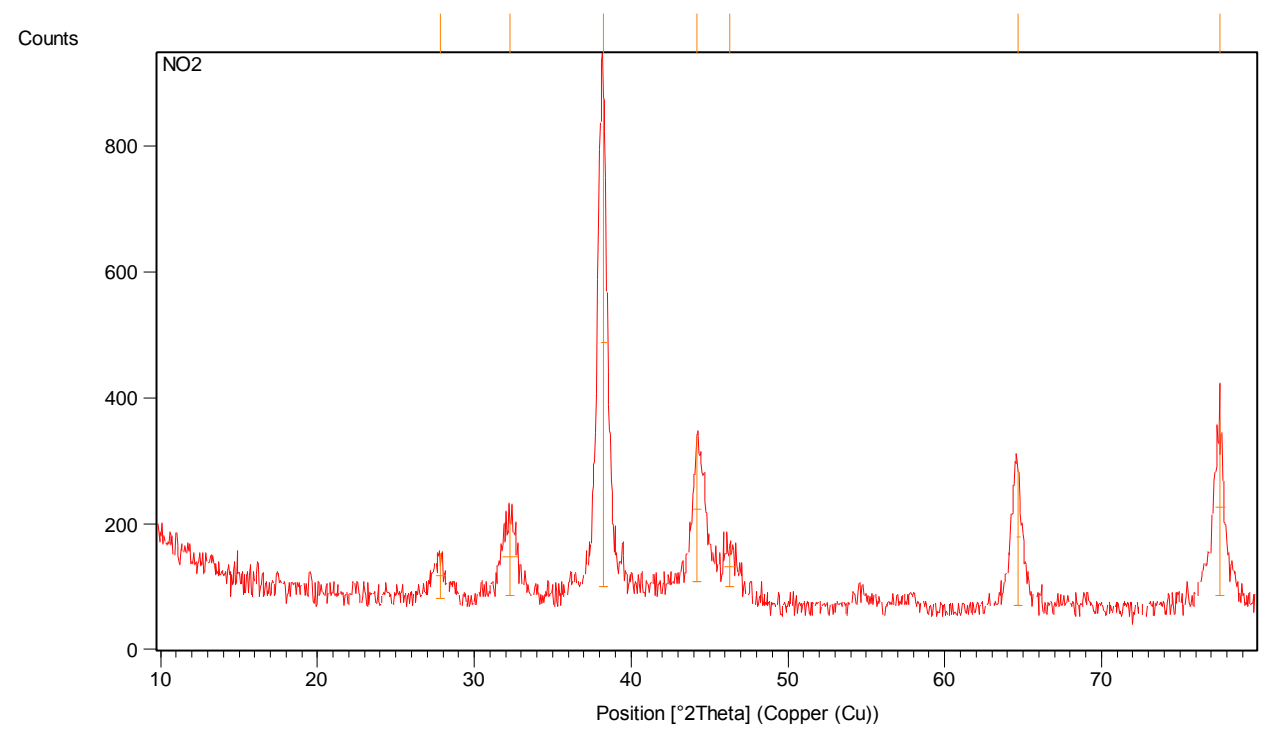

Figure 11. XRD image of Ag NPs using Scropholaria Striate extract 
The average size of crystalline beads is obtained by calculating the peak widths of the specimens using the DebyeScherer formula (Formula 1) (Table 1): $\mathrm{D}=0.9 \kappa / \beta \cos \Theta$

Where $\mathrm{D}$ is the mean size of crystalline beads, $\beta$ : full-width at halfmaximum (FWHM), and $\kappa$ : wavelength of x-rays. The average size of synthesized crystalline beads estimated by the Debye-Scherrer formula was $22.08 \mathrm{~nm}$, which is in agreement with the results of the TEM and the results obtained from the spectrum of ultraviolet-visible spectroscopy.

Table 1. Precise details for calculating silver NPs size

\begin{tabular}{cccccc}
\hline NO & Pos. [ ${ }^{\circ} \mathbf{2 T h}$. $]$ & FWHM [ ${ }^{\circ}$ 2Th.] & hkI & d-spacing [̊] & Siz(nm) \\
\hline $\mathbf{1}$ & 38.2683 & 0.3936 & 111 & 2.35198 & 21.388 \\
$\mathbf{2}$ & 44.1964 & 0.4920 & 200 & 2.04930 & 17.56 \\
$\mathbf{3}$ & 64.657 & 0.2952 & 220 & 1.44161 & 31.862 \\
$\mathbf{4}$ & 77.538 & 0.5904 & 311 & 1.23116 & 17.54 \\
& & & & & Ave=22.08 \\
\hline
\end{tabular}

FT-IR spectroscopy

To identify functional groups that are responsible for the biosynthesis of silver NPs, FT-IR spectroscopy was used. The FT-IR spectrum taken from the extract of Scropholaria Striate (before reaction with $\mathrm{AgNO}_{3}$ ) and the silver NPs synthesized by this extract (after reaction with $\mathrm{AgNO}_{3}$ ) are shown in Figure 12. It can be seen that both FT-IR spectra show a change in the following peaks: 3413-3414 (due to the stretching of $\mathrm{O}-\mathrm{H}$ from phenol and carboxylic acid), 2923-2924 (due to Alcanian C-H stretching), 1616-1618 (due to Alkin $\mathrm{C}=\mathrm{C}$ stretching) and 1051-1070 (due to phenolic C-O stretching). In addition, peak 1637 centimeters per ${ }^{\circ} \mathrm{C}$, is related to the stretching of the carbonyl group $(\mathrm{C}=\mathrm{O})$ in the Scropholaria Striate extract, but this peak is absent in the synthesized silver NPs. This shows that the carbonyl group in the extract is involved in reducing the silver ions [23].

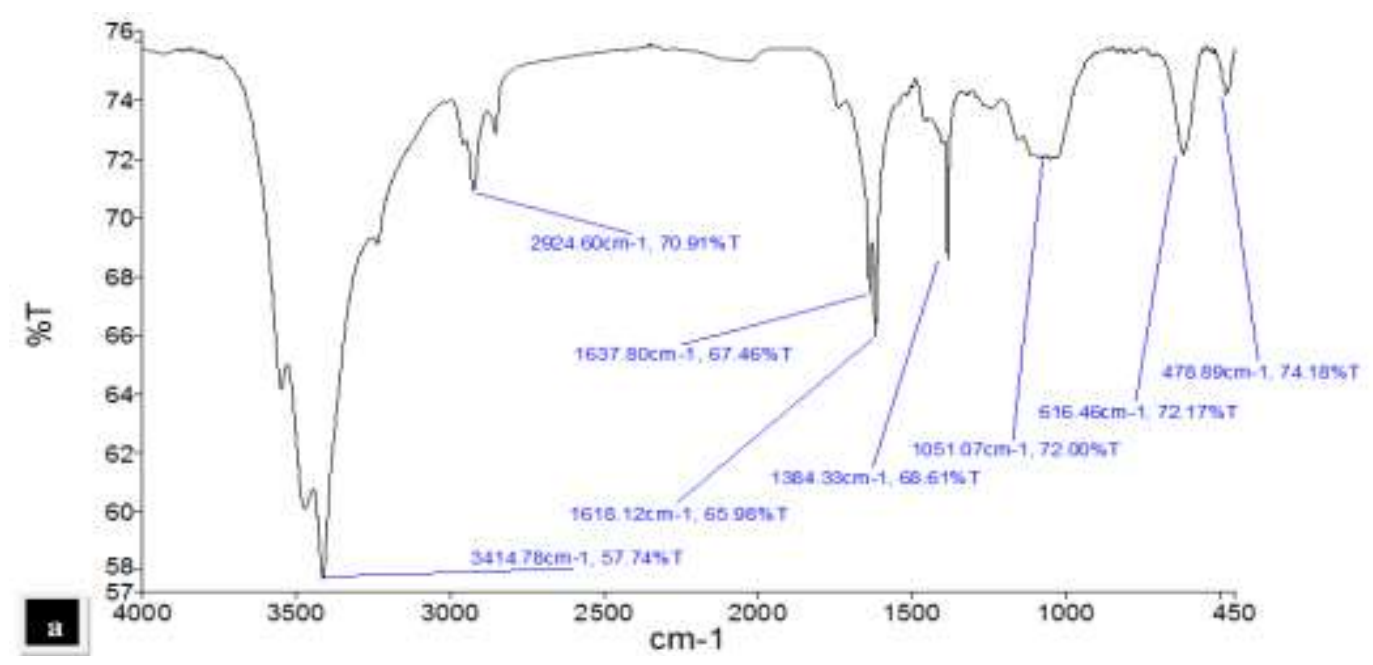




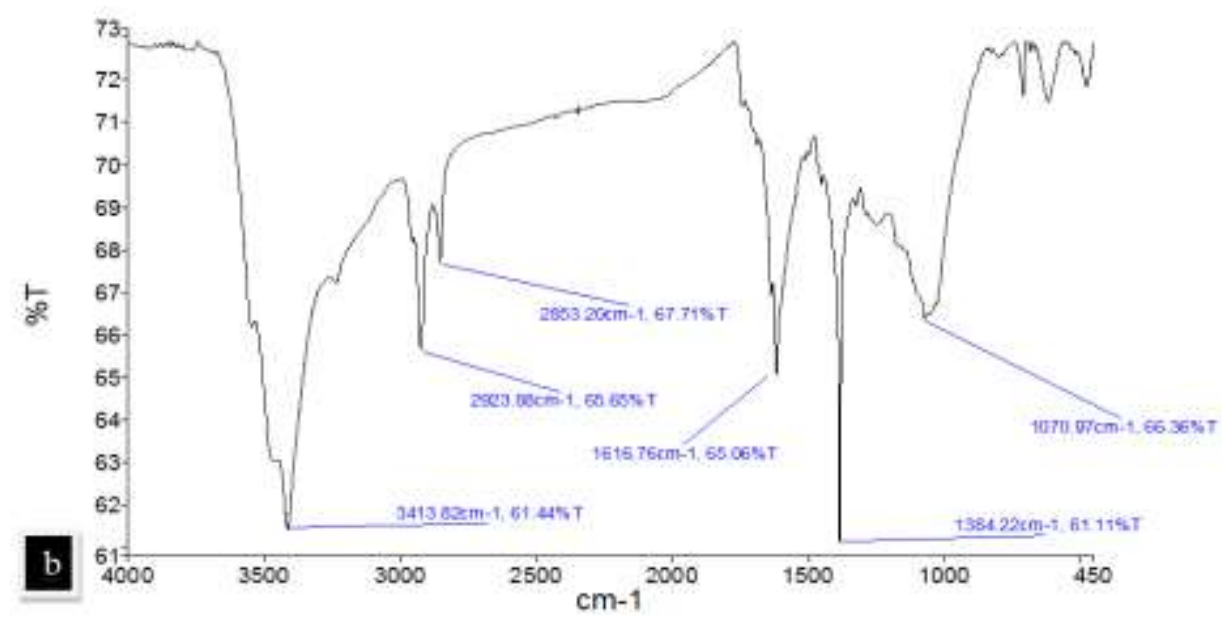

Figure 12. FTIR spectra of a) Scropholaria Striate and b) Ag NPs synthesized from the peel extract

\section{DLS spectrum}

The way of distribution of silver particles was determined using the DLS. The average particle size measured by DLS is $126.3 \mathrm{~nm}$, as shown in Figure 13. The particle size measured by the DLS analysis is higher than that by the TEM analysis. This may be due to the detection of small amounts of large particles measured by agolomer or contamination, which causes uncertainty in particle size.

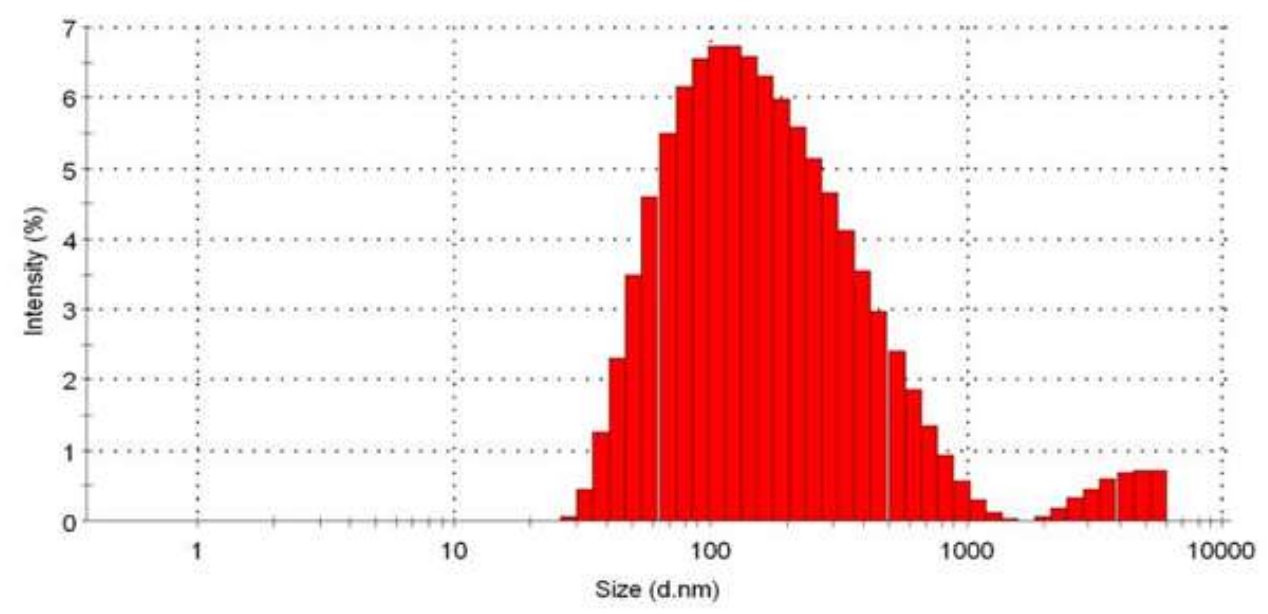

Figure 13. Diagram of treated silver NPs size distribution with Scropholaria Striate extract

Significant differences in both analyzes probably indicate that TEM only measures the distribution of physical size by number, and does not include any limiting factor, while the DLS measures the hydrodynamic diameter (particle diameter) with ions or molecules that are attached to the surface, as well as AgNPs in the solution [23].
Comparison of our study with previous works

The merit of the present work has been compared with others for the synthesis of silver NPs (Table 2). According to the obtained results, our method shows a more satisfied results regarding to particle size. As shown in Table 2, with using of Scropholaria Striate, the size of $\mathrm{Ag}$ NPs is about $20 \mathrm{~nm}$ which is smaller than previous methods (Entry 9). 
Table 2. comparison of present method for preparation of silver NPs using different plant extracts

\begin{tabular}{cccccc}
\hline Entry & Plants extract & Size $(\mathbf{n m})$ & Plant's part & Shape & References \\
\hline $\mathbf{1}$ & Butea monosperma bark & 35 & Bark Plant & Face-Centered Cubic & 24 \\
$\mathbf{2}$ & Ziziphora tenuior & $8-40$ & Leaves & Spherical & 25 \\
$\mathbf{3}$ & Vitis vinifera & $30-40$ & Fruit & - & 26 \\
$\mathbf{4}$ & Alternanthera dentate & $50-100$ & Leaves & Spherical & 27 \\
$\mathbf{5}$ & Boerhaavia diffusa & 25 & Whole plant & Spherical & 28 \\
$\mathbf{6}$ & Psoralea corylifolia & $100-110$ & Seeds & - & 29 \\
$\mathbf{7}$ & Melia dubia & 35 & Leaves & Spherical & 30 \\
$\mathbf{8}$ & Ferula gumosa & 30 & Leaves & Spherical & 31 \\
$\mathbf{9}$ & Scropholaria Striate & 22 & Whole plant & Spherical \& FCC & This Study \\
\hline
\end{tabular}

\section{Conclusion}

The study showed that Scropholaria Striate leaf extract has high potential for silver NPs production. The production of NPs in this way is singlestep and cost-effective, and the process is completed in very little time. The change in the color of the solution from transparent to brown and also the increase in the absorbance of the solution were due to the reduction of silver ions and their accumulation in the form of silver NPs.

\section{Acknowledgments}

The authors gratefully acknowledge Islamic Azad University of Arak for financial support of this project.

\section{References}

[1] T. Mohasseli, S.h. Pourseyyedi, Biotechnol Tarbiat Modares Univercity., 2015, 1, 10-20 (Persian).

[2] S. Ahmed, M. Ahmad, B.L. Swami, S. Ikram, J. Adv. Res., 2016, 7, 17-28.

[3] M. Halimi, M. Nasrabadi, N. Soleamani, N. Rouhani, Asian. J. Nanosci. Mater. 2019, 1, 19-24.

[4] R. Shaikh, I. Zainuddin Syed, P. Bhende, Asian. J. Green. Chem., 2019, 3, 70-81.

[5] M. Sharma, S. Yadav, M. Srivastava, N. Ganesh, Sh. Srivastava, Asian. J. Nanosci. Mater., 2019, 1, 244261.
[6] M.A. Nasseri, M. Shahabi, A. Allahresani, M. Kazemnejadi, Asian. J. Green. Chem., 2019, 3, 382-390.

[7] M. khodaei, N. Ghasemi, M. Ramezani, Iran. Chem. Commun., 2014, 2, xxx-xxx.

[8] N. Ahmad, S. Sharma, M.K. Alam, V.N. Singh, S.F. Shamsi, B.R. Mehta, A. Fatma, Coll. Surf Bio Interfaces., 2010, 81, 81-86.

[9] J.L. Gardea-Torresdey, E. Gomez, J.R. Peralta-Videa, J.G. Parsons, H. Troiani, M. Jose-Yacaman, Langmuir., 2003, 19, 1357-1361.

[10] A.G. Dwivedi, K. Gopol, Coll Surf A: Phys Eng Asp., 2010, 360, 27-33.

[11] S.S.K. Kamal, H.R.S. Prasanta, V. Johnson, P. Manda, R. Shankar, D. Loganathan, Acta Chim Slov., 2010, 57, 808-12.

[12] P. Ghorbani, D. Hamidialamdari, F. Namvar, P. Yaghmaei, J Ilam Uni Med Sci., 2016, 7, 181-189 (Persian).

[13] S. Iravani, B. Zolfaghari, Biomed Res Int., 2013, 78, 1-5.

[14] G. Von White, P. Kerscher, R.M. Brown, J.D. Morella, W. McAllister, D. Dean, C.L. Kitchens, J. Nanomaterials., 2012, 26, 1-12.

[15] F. Rad, F. Aala, N. Reshadmanesh, R. Yaghmaie., Indian $J$ Dermatol., 2008, 53, 115-118. 
[16] A.A.S. Sefidgar, A.A. Moghadamnia, A. AkhavanTafti, M. Sahebjami, M. Heydari, M. Motallebnejad, Caspian Journal of Internal Medicine, 2010, 1, 47-49.

[17] A. Morshedi, M.H. Dashti Rahmatabadi, Dehghan Harati, M., M.A. Bagheria Nasab, S. Salami. Journal of Medicinal Plants, 2011, 10, $48-57$.

[18] M. Negahban, S. Moharramipour, F. Sefidkon, Journal of Asia-Pacific Entomology, 2006, 9, 61-66.

[19] R. Dimitrijević's O. Cvetkovic, Z. Miodragovic, V. Jovic, J. Min. Metall. Sect. B-Metall., 2013, 49, 91-95.

[20] A. Sudha, J. Jeyakanthan, P. Srinivasan, Resource-Efficient

Technologies, 2017, 000, 1-10.

[21] M.R. Mollick, S. Pattanayak, D. Maity, C. Sharmila, S.K. Dash, S. Chattopadhyay, S. Roy, D. Chattopadhyay, M. Chakraborty, J. Saudi Chem. Society., 2017, 21, 673684.

[22] R. Sithara, P. Selvakumar, C.A.S. Anandanb, P. Sivashanmugam, J. Adv. Res., 2017, 8, 561-568.

[23] S. Roy, T. Mukherjee, S. Chakraborty, T.K. Das, J. Nanomat Bios., 2013, 8, 197-205.
[24] S. Pattanayak, M.R. Mollick, D. Maity, C. Sharmila, S.K. Dash, S. Chattopadhyay, S. Roy, D. Chattopadhyay, M. Chakraborty, J. Sau. Chem. Soci., 2017, 21, 673-684.

[25] B. Ulug, M.H. Turkdemir, A. Cicek, A. Mete, Bio. Spect., 2015, 135, 153-161.

[26] K. Paulkumar, G. Gnanajobitha, M. Vanaja. S. Rajeshkumar. C. Malarkodi, G. Annadurai, C. Kannan, J. Nano. Chem., 2013, 3, 1-6.

[27] J.N. Reddy, M. Rani, A.K. Gupta, S.S. Rani, J. M. Chem., 2014, 85, 784794.

[28] Q. Sun, X. Cai, J. Li, M. Zheng, Z. Chenb, C.P. Yu, Colloid Surf A: Physicochem Eng Aspects., 2014, 444, 226-231.

[29] P. Adhyapak, S. Danai-Tambhale, Inter. J. Phar. Bio Sci., 2014, 5, 457467.

[30] V. Kathiravan, S. Ravi, S. Ashokkumar, Spect. Acta Part A: Mole. and Biom. Spect., 2014, 130, 116-121.

[31] F. Mohammadi, M. Yousefi, R. Ghahremanzadeh, Adv. J. Chem. A, 2019 ,

DOI: 10.33945/SAMI/AJCA.2019.4.2.

How to cite this manuscript: Tayeb AB Matin, Nahid Ghasemi, Keivan Ghodrati, Majid Ramezani. "Green synthesis and characterization of silver nanoparticles using Scrophularia Striata extract”. Eurasian Chemical Communications, 2019, 494-506. 